\title{
Research on the Training Model of High-skill Talent under the Background of Industrial Upgrading in China
}

\author{
Jian-Hua He \\ Beijing Normal University, Zhuhai, Guangdong, China, 519085 \\ hrstudy@163.com
}

Keywords: Industrial upgrading, High-skill talent, Vocational education, Training model.

\begin{abstract}
The paper analyzes the history and trend of industrial structure change in China and the demand of high -skill talent under the background of industrial upgrading. Then the author points out that there are four models in high-skill talent training: college model, enterprise model, college enterprise co-operation model, and social model. To improve the level of high-skill talent, those four models should play important roles to satisfy the human resource demand of industrial upgrading.
\end{abstract}

\section{Introduction}

High-skill talent is the person in production transportation and service industry who master professional knowledge and technology, has high skills, can solve the key operation problem of technology and process in practice. [1] High-skill talent include the person who gets national vocational qualification certificates, such as primary middle and senior technical rank or corresponding professional rank, also include technical personnel who works in the enterprise but didn't achieve corresponding qualification certificates. High-skill talent is not only the key human resource of China's technology worker, but also an important force to accelerate industrial upgrading, improve enterprises' competitiveness, to promote technological innovation and develop transformation of scientific and technological achievements.[2]

Industrial upgrading is based on the perspective of global value chain, industry evolves from low technical level, low value-added status to high-tech level and high value-added status.[3]Industrial upgrading will inevitably bring factor upgrading, enterprise's requirements for quality of human resources must be improved, especially demand for high-skill talents be rising. However, the phenomenon of high-skill talent shortage in China is very serious at present, which has affected China's industrial upgrading and economic growth rate. Establish the training system for high-skill talents, and enhance the high-skill human capital stock effectively has a very important significance for promoting China's industrial upgrading, maintaining social harmony and stability, and advancing the healthy and sustainable development of economy.

\section{Analysis of the demand structure of high-skill talents during China's industrial upgrading \\ The evolution of industrial structure upgrading since the reform and opening in China}

Since the reform and opening, China seizes the historical opportunities, based on stabilizing growth, adjusting structure, promoting reform, gains sustained and rapid economic growth for nearly 30 years, industrial structure completes the evolution from lower stage to higher stage. The proportion of the first industry in GDP appear the trend to decline continuously. From1979 to 2013, the proportion of first industrial added value in GDP dropped from $31.3 \%$ to $10 \%$. The proportion of the second industry first increased and then decreased, declined from $47.1 \%$ to $43.9 \%$. The proportion of the third industry continuously optimized, rising from $21.6 \%$ to $46.1 \%$. [4] In 2013, the proportion of third industry added value exceeded the second industry for the first time; the type of industrial structure has been changed from one, two, three to three, two, one. The industrial development breaks out of the situation 'weak agricultural foundation, abnormal industrial expansion, and backward service industry', industrial structure has gradually become more rational, achieved the optimization and upgrading, national comprehensive strength and international influence realizes to the historical leap. 
However, there are still a series of problems urgently to be improved in the process of industry development in China. For example, the three industry and its internal structure is unreasonable; the third industrial development is still lagging behind the international level; independent innovation ability is insufficient; the resources and energy consumption is high; the development of regional economy is unbalanced. Therefore, in the new historical period, China's industrial structure adjustment should stand in the height of the global value chain, be based on the sustainable development of the rational allocation of resources and environment, and focus on the development of advanced manufacturing and modern service industry, aim to enhance the efficiency and effect of the industries transferring and upgrading.

\section{Analysis of the demand structure of high-skill talent at the process of China's industrial upgrading}

The relationship between the industrial structure and the demand structure of human resources is of interdependence and interaction. The development status of the industrial structure determines the quantity and quality of countries or regions' human resources needs; the quantity and quality of human resource is the skill foundation of national or regional industrial upgrading, which is directly related to the direction and effect of the national or regional industrial upgrading.

The pace of China's industrial transferring and upgrading speeds up and is resulted in changes in the demand structure of human resource. In recent years, the frequent occurrence of labor shortage phenomenon reflects this subtle change to a certain extent. The survey found that the shortage of human resources is not a simple sense of shortage of migrant workers, but a kind of structure shortage or shortage of skills, which means that the shortage is high-skill workers rather than ordinary workers. The survey by Ministry of human resources and social security shows that the high-skill talents that enterprise most need are: marketing, mechanics, senior mechanics, technicians and senior technicians, the demand ratio is respectively $14.4 \%, 12.1 \%$ and $10.9 \%$.[5] The demand number of high-skill talents is 2.5 times to the actual number[6]. The phenomenon of shortage of skills is be caused by many reasons, one of the most important reason is uncoordinated between industrial structure and employment structure, and the reality supply of human resources cannot meet the business' needs for high-skill talents. The essence of shortage of skills is under a kind of non-full employment conditions, human resources have not been rational develop and employment structure lags behind industrial upgrading in a short-term.

In order to match the trend of industrial upgrading from the elements structure, the demand for high-skill talents in China's future must be estimated. According to the forecast, in 2015 and 2020, China's demand for skilled workers will increase nearly 19 million and 32.9 million than in 2009. (Excluding the current skilled workers gap of 9.3 million). Among them, the demand for high-skill talents will increase to about 5.4 million and 9.9 million (excluding the current high-skill gap of 4.4million). [7] In current China, employees' overall education standard has a large gap compared with the medium developed countries in the second and third industry. The proportion is low that personal has a technical title or a technical grade certificate, and the high-skill talents are lack. Therefore, in the future, China should promote the employment population of the first industry transferring to the second and the third industry, increase the appropriate employment proportion of the second industries, train and attract more talents to the third industry, improve the quantity and structure of the proportion of the three industry gradually, improve the technical level of workers of the second or third industry, and pay attention to the training and introduction of high-skill talents.

\section{Analysis of China's present situation and reasons for the shortage of high-skill talents \\ The shortage of high-skill talents in China}

Driven by the industrial upgrading, labor intensive industries begin transforming to capital and technology intensive industry, the enterprises' demand for low-end production workers will gradually slow down; demand for high-skill talents will continue to increase.

In recent years, the scale of high-skill talents in China has expanded, and the structure gradually 
optimized. As of the end of 2013, there are 150 million skilled workers in China, accounting for $19 \%$ of the total employee; 37.624 million high-skill talents, accounting for $25.2 \%$ of the total amount of skilled workers. [8] Compared to the proportion of $40 \%$ in developed countries, there is still a big gap of the number of high-skill talents in china. In terms of structure, there are more high-skill talents in the large and medium-sized state-owned enterprises than in the private enterprises and in small and medium-sized enterprises; there are more high-skill talents in traditional mechanical processing industries than in new industries and modern manufacturing industry; More than $40 \%$ technicians and senior technicians are over the age of 46; The issues of shortage of young high-skill talents is more prominent.[9] In general, the contradiction between high-skill talents training and the demand for high-skill talents in the economic development in China is prominent. The amount of high-skill talents is shortage, and the structure is unreasonable; leading high-skill talents are still shortage; Mechanism obstacle of high-skill talents development and social environment needs to be improved etc., all these problems have been unable to meet the needs of social and economic development in China. It can be said, it is imminent to cultivate of high-skill talents to improve the innovation ability of the whole country.

\section{Analysis of the reasons of the shortage of high-skill talents in China}

High-skill talents structure and industrial structure are closely related, it needs qualified high-skill talents in support of industrial upgrading, and the quantity and structure of high-skill talents affect the industrial upgrading and adjustment. [10] At present, the number and structure of high-skill talents in China cannot meet the requirements of industrial upgrading, especially the requirements in advanced manufacturing industry and modern service industry cannot be met effectively.

Many reasons caused the shortage of high-skill talents in China, it can be summed up in the following aspects: firstly, the overall investment of high-skill talents training is shortage, and there are many shortcomings in the current education system and the cultivation mechanism of high-skill talents; secondly, the ability of training institutions supplying vocational and technical education is weak, unable to meet the demand of industrial upgrading; thirdly, the social recognition of high-skill talents are still biased, the traditional concept of take academic education seriously and set vocational education at naught; take diploma seriously and set skill at naught has not been reversed, the enthusiasm of workers wanting to learn skills is not high; finally, the identification and evaluation mechanism for high-skill talents is not perfect, the problems of limit space for skill talents' development and the low salary are unable to form an effective incentive to employees. [11][12]

Through the analysis of the causes of the shortage of high-skill personnel, we believe that education and training is the most convenient channel to solve the shortage of high-skill talents. We can take improving the overall quality of skilled workers as the breakthrough point to increase the investment of human capital, to build a high-skill talents force, to adapt to the adjustment optimization, and upgrading of China's industrial structure, and to provide the necessary human resources for the industrial upgrading.

\section{Analysis of the training model of high-skill talents under the condition of industrial upgrading}

Cultivation of high-skill talents involves in nation, college, enterprise, social training institution, individual and other subject, which play a very important role in the aspect of high-skill talents' cultivation. According to the different subject of cultivating high-skill talents, there are four main models in the high-skill talents training in China: the college training mode, the enterprise training mode, the cooperation training mode with college and enterprise, and social training mode. In the critical period of industrial upgrading, the above-mentioned modes should play important roles in cultivating high-skill talents to provide human resources for China's industrial upgrading.

\section{Focus on the construction of the college training mode with the higher and secondary occupation education as the main body, to improve the quality of personnel training}

The college training mode is a kind of based mode with the higher and secondary occupation education as the main body, through the theory study and practice teaching together to cultivate high-skill talents. Aiming at the existing problems of China's occupation education, it needs to be 
improved from the following aspects, to improve the training quality of high-skill talents :( 1) the government should improve the status of occupation education in the national education system; the occupation education should have equally important position with basic education and higher education. The society should change the dislocation cognitive phenomenon for the value of occupation education, and employee's should enhance occupation cognitive for high-skill jobs; (2) Combination of industrial upgrading trend, the college should forecast the demand for high-skill personnel, timely adjust the major of occupation education to adapt to the demand of industrial structure, economic structure and technological structure, and the occupation education should play the basic role for high-skill talents training; (3) Combined with the requirements of industrial upgrading, the college should know the jobs and skills requirements of high-skill talents, and improve the content of the course and teaching methods according to the ability requirement. According to the market demand, the college should constantly revise the talent training scheme, increase the proportion of practical skills training in basic theory teaching; (4)According to the adjustment of industrial structure, the college should actively carry out the construction plan of the double teachers, encourage teachers to adopt flexible teaching methods, strengthen the teaching practice to improve the students' learning initiative; (5)Abandoning the traditional mode of closed training system, the college should fully rationally use of social resources to strengthen the all-round cooperation with the enterprise.

\section{Advocate the enterprise training mode with enterprise training as the main way to speed up the cultivation of high-skill talents}

The practical and operational character of the high-skill talents' work determines high-skill talents gaining and improving the skills must be through practice and accumulation of experience. Enterprise is not only the employment units of high-skill talents, but also the cultivation place of high skilled talents. Speeding up the cultivation of high-skill talents of enterprises, it needs to do the following: (1) The enterprise should attach great importance to the training of high-skill personnel training work, increase the expenditure. The government can also encourage enterprises to organize high-skill talents training activities through prefer-ential policies; (2) the enterprise can combine with the national high-skill personnel training plan, adopt flexible training mode to promote employees' job skills. Enterprises can use not only mentoring method, learning by doing and other traditional methods, but also skill competition, job rotation, Experts consultation and other new ways to organize the training, even establish skill-master studio or high-skill talents training workshop in enterprises; (3) The enterprise should support and encourage employees to participate in the occupation skill training, creative skills transfer environment for employees, and improve employee's technical ability to solve practical problems; (4) improve the high-skill personnel' salary, formulate career development planning for high-skill talents, and encourage employees commit to lifelong learning.

\section{Strengthen the cooperation of government colleges and enterprises; promote the training mode of college-enterprise cooperation to satisfy the requirements of the times of industrial upgrading}

College-enterprise cooperation in education is both college and enterprises participate in the process of personnel training, focusing on training students' comprehensive quality and employment competitiveness. This mode takes use of colleges and enterprises, two different educational environment and educational resources, through lectures and practice, to cultivate high skill talents. [13]Strengthening college-enterprise cooperation is an inevitable requirement of the industrial upgrading, only strengthen cooperation can achieve the balance of high-skill talents supply and demand.

In the context of industrial upgrading, improving the quality of college-enterprise cooperation need strengthen the work of the following aspect: (1) The college-enterprise cooperation need actively learn from the developed countries' advanced experience of cultivating high- skill talents such as training mode of dual system in German, explore suitable high-skill personnel training mode of

college-enterprise cooperation adapting for China's national conditions. In the 
cooperation, enterprises must be as the main body, the occupation college must be as the foundation, we can make college education and enterprise training in a close contact; (2) The government should actively promote the college-enterprise cooperation through the platform built, policy improved, mechanism constructed, publicity increased and other means; (3) The college should pay close attention to the needs of enterprises, carry out all-round, multiple forms of cooperation with the enterprise to promote the effectiveness of training high-skill talents; (4) The enterprises should combine the production requirements, realize the sharing of resources, mutual reciprocity and mutual benefit, cooperate with the technical college to train high-skill talents to meet the enterprises' needs, through drawing up training objectives together, developing training programs together, and providing equipment and teacher supports. [14]

\section{Improve the social education mode based on public training as the main body; establish multi-level training system of high-skill talents}

The social education mode is the market-oriented mode based on social training institutions as the main body, to provide professional skills training for all workers. It is a supplement mode with college training mode and enterprise training mode. At present, the public training base is the main form of China's social training mode. In accordance with the provisions of China's high-skill personnel development plan and high-skill talents revitalization plan, the country will build 1200 high-skill personnel training bases in 2020. These bases will focus on the development of high-skill personnel training, high-skill talent evaluation, occupation skill competition, curriculum development, achievement exchange and other activities. [15]

In the background of industrial upgrading, the construction of social education with public training as the main body, need to pay attention to the following three aspects: (1) In the aspect of training object, the social training mode should be geared to the needs of society workers, especially for laid-off workers and migrant workers. The focus is to change the new generation migrant workers to the junior or intermediate technical workers; (2) in the direction of the training, the social training mode should put the importance on supply high-skill talents for the demand of industrial development in the local region. According to the principle of 'market-oriented, reasonable positioning, resource sharing, function complementary, the government should plan the layout of social training institutions to meet the needs of the local industrial development and the high-skill personnel, in order to solve the problem of local high-skill talent training; [16] (3) in the aspect of operation mechanism, the government should integrate social resources, implement the three-in-one mechanism of the government as leader, enterprises as the main body, the training institution as basics [17] The government can improve the basic conditions of training institutions through investment or subsidies, enterprises can provide training demand and employment position, and training institutions can build high-skill personnel training service platform.

\section{Acknowledgement}

This research was financially supported by Guangdong Province Philosophy Social Science Fund.

\section{References}

[1] Li Yuanyue, Wu Guowei. High-skill talent ecological imbalance and Countermeasures [J]. Science and technology management research, 2011, (2): 104-107.

[2] General Office of the CPC Central Committee and the General Office of the State Council views on further strengthening the work of high-skill talent [R]. http://www.sina.com.cn, 2006-06-11.

[3] Chen Yu, Kuang Guoliang. Industrial upgrading theory and research ideas [J] the Reform, 2009, (10): 85-89.

[4] National Statistics Bureau of the people's Republic of China. Statistical Communique of the People's Republic of China of National Economic and social development in 2013 [R], http://www.ybzjj.gov.cn/html/2014-02/15839.html, 2014-02-24. 
[5]The research group of Ministry of Labor and Social Security. The report of the skilled workers shortage. [J] The labor and Social Security Research Communication, 2004 (11): 39-41.

[6] Liu Libin, Chen Yian, Liu Luning. The influence factors of high-skill personnel supply imbalance in the background of industrial transformation: a case study of Beijing city [J]. China Human Resources Development, 2013, (1): 10-15.

[7] The Central Organization Department, Ministry of Human Resources and Social security. The construction of high-skill talents and long-term planning (2010-2020)[R]. http://www.mohrss.gov.cn/SYrlzyhshbzb/ldbk/rencaiduiwujianshe/jinengrencai201107/t20110728_ 86941.htm.

[8] Cui Yujuan. The ten years practicing skills Chinese youth mission [N]. China Youth Daily, 2014-11-04.

[9] Yang Tao, Yang Shuzhen. A serious shortage of high-skill personnel in our country [N]. People, http://finance.people.com.cn/BIG5/n/2013/0320/c70846-20852394.html, 2013-03-20.

[10] Wang Jun, Lv Hongfen. The link of High-skill talents and the industrial structure: a study of the case of Zhejiang, [J] Higher Engineering Education. (1):67-72. 2011.

[11] Yang Wansu, Wu Youming, Yan Honghe. Study on the reason analysis and Countermeasure of the shortage of high-skill talents of our country.[J] Science and Technology Forum in China, 2006, (3):120-123.

[12] Su Zhigang. Exploration on how to improve high-skill talents team. [J]the Economic Problems, 2003, (8):14-16.

[13] Sun Weihong. Exploration of school enterprise cooperation training mode of high-skill talents. [J]Education Development, 2006 (4): 23.

[14] Gao Yan. Exploration of the growth of high-skill talents.[D].Northeastern University doctoral thesis, 2008, 5:10.

[15]Human Resources and Social Security Ministry, the Ministry of Finance. The implementation plan of national high-skill talents revitalization plan. [R]http://www.mohrss.gov.cn/ SYrlzyhshbzb/ldbk/rencaiduiwujianshe/jinengrencai/201404/t20140425_129117.htm.

[16][17] Wu Xiaotian. The practice and exploration of public training base [D]. East China Normal University, 2009, 9:140. 